\title{
Influence of time at which oxytocin is administered during labor on uterine activity and perinatal death in pigs
}

\author{
DANIEL MOTA-ROJAS* , DINA VILLANUEVA-GARCÍA ${ }^{\dagger}$, \\ ELVIA Y VELÁZQUEZ-ARMENTA ${ }^{\ddagger}$, ALEJANDRO A NAVA-OCAMPO „, \\ RAMIRO RAMÍREZ-NECOECHEA* , MARÍA ALONSO-SPILSBURY*, \\ and MARÍA E. TRUJILLO ${ }^{\S}$
}

\begin{abstract}
*Department of Animal Production \& Agriculture, Research Area: Ecodesarrollo de la Producción Animal, Universidad Autónoma Metropolitana-Xochimilco, México DF, Mexico, ’Division of Neonatology, Hospital Infantil de México Federico Gómez, México DF, México, ${ }^{\ddagger}$ Pharmareasons, Toronto ON, Canada, IDDivision of Clinical Pharmacology \& Toxicology, The Hospital for Sick Children, Toronto ON, Canada, and ${ }^{\S}$ Department of Animal Production: Swine, Facultad de Medicina Veterinaria y Zootecnia, Universidad Nacional Autónoma de México, México DF, México
\end{abstract}

\begin{abstract}
Oxytocin is extensively used to induce or augment uterine contractions, especially to facilitate the third stage of labor in humans. Administration of oxytocin to parturient sows reduces duration of labor whereas mortality of the offspring may remain unchanged. This study aimed to evaluate whether time of administration of oxytocin during parturition may alter the uterine response and fetal outcomes. Two hundred parturient sows were randomly assigned to intramuscularly receive either saline solution (control group) or oxytocin 0.083 $\mathrm{IU} / \mathrm{kg}$ immediately after the delivery of the $1^{\text {st }}, 4^{\text {th }}$ or $8^{\text {th }}$ piglet (groups O-1, O-4 and O-8, respectively). Uterine effects and fetal outcomes were registered in all groups. The duration of labor was 20-40 min shorter $(P<0.0001)$ and time interval between babies was reduced by $3-5 \min (P<0.0001)$ in the three groups receiving oxytocin. The duration and intensity of contractions, meconium-stained piglets and intrapartum deaths decreased as time at which oxytocin administered during labor was increased. In group O-8, we observed approximately $70 \%$ less meconium-stained piglets and intrapartum deaths than in the control group. In conclusion, oxytocin administered at early phases of parturition to sows may increase duration and intensity of uterine contractions as well as adverse fetal outcomes.
\end{abstract}

Key terms: Fetal distress, Fetal monitoring, Obstetric labor, Oxytocin, Uterine contractions

\section{INTRODUCTION}

Oxytocin is extensively used to induce or augment uterine contractions, especially to facilitate the third stage of labor in humans (Golan et al., 1983; Reddy and Carey, 1989; Wilken-Jensen et al., 1989; Golan,1990). It is also being used in more than $80 \%$ of swine farms in United States for complementing normal parturition (Straw et al., 2000), probably in attempt to decrease the approximately $5-15 \%$ of stillbirths observed in such farms
(Leman et al., 1972). However, although administration of oxytocin to parturient sows reduced duration of labor, mortality of the offspring remained unchanged (Randall, 1972; Gilbert, 1999; Mota-Rojas et al., 2002). A critical aspect to be noticed in these studies is that oxytocin was administered at the beginning of labor, when more than 10 piglets still remained to be born.

In a dose-response study of oxytocin administered to sows early during labor, we recently demonstrated that oxytocin 0.083

Corresponding author: Alejandro A. Nava-Ocampo, M.D., Division of Clinical Pharmacology \& Toxicology, The Hospital for Sick Children, 555 University Ave., Toronto ON, M5G 1X8, Canada. Fax: +(416) 873 7562. E-mail: navaocampo_aa@yahoo.com 
IU/kg significantly decreased the mortality rate of piglets compared to higher doses (Mota-Rojas et al., 2005). Our findings supported the possibility that certain dose regimens of oxytocin may increase offspring survival rate in pigs. In order to extend the knowledge regarding the relationship between oxytocin administration and fetal outcomes, this study aimed to evaluate whether time of administration of oxytocin during parturition may alter the uterine response and fetal outcomes.

\section{EXPERIMENTAL PROCEDURES}

Animal selection: The study was performed in a commercial farm of 2,000 hybrid Yorkshire-Landrace adult sows with approximately 350-400 planned deliveries per month, allowing us to select 200 animals for the study from one batch only and to complete the experiments in a 1-month period. The study was approved at the Department of Animal Production \& Agriculture, Universidad Autónoma Metropolitana-Xochimilco, México DF, Mexico, and was performed in accordance with the guidelines of the ethical use of animals in applied ethology studies described elsewhere (Sherwin et al., 2003). It was assumed that procedures added mild pain, suffering and distress to that expected during standard attention in the labor process. Cell phones, televisions or other source of noise were not allowed in the production and delivery areas in order to decrease the sources of stress, and animals were treated humanely throughout the study.

Sows were artificially inseminated and received prenatal care throughout pregnancy including a diagnostic ultrasound (Renco Pregnant-Alert, Minneapolis MN, USA) at 5 weeks of pregnancy. Animals included in the study weighed from 156 to $302 \mathrm{~kg}$ at the time of parturition, and were in their first to fifth pregnancy. Animals with a back fat of $\geq$ $26 \mathrm{~mm}$ identified by ultrasound were excluded from the study in order to control disposition of intramuscular administration of oxytocin. Sows were housed for 5 days before the expected delivery date in individual pens of 4 to $6 \mathrm{~m}^{2}(2 \mathrm{~m} \times 2 \mathrm{~m}$ or 3 $m \times 2 m$ ) with a cement floor surface. Sows were not restrained and were provided with straw 4-8 hours before the beginning of parturition. The animals were fed daily with $1 \mathrm{~kg}$ three times a day (3 $\mathrm{kg}$ per day) of a concentrate with $12.3 \mathrm{MJ} \mathrm{ME} / \mathrm{kg}$ and $15 \%$ of crude protein.

Delivery time was controlled by prostaglandins (Lutalyse, Pharmacia \& Upjohn, México DF, Mexico) intramuscularly administered 36 hours prior to the expected delivery date in all sows.

Procedures: By means of a predesigned table of random numbers for groups balanced in gravidity, 200 animals were allocated to the following 4 groups of 50 sows per group. In group 1 (controls), animals received intramuscularly saline solution $(0.9 \% \mathrm{NaCl})$. Animals in groups O-1, O-4 and O-8 received intramuscularly oxytocin (Oxipar, Anchor, Guadalajara, Jalisco, Mexico) at a dose of $0.083 \mathrm{IU} / \mathrm{kg}$ (approximately $1 \mathrm{IU} / 12 \mathrm{~kg}$ ) immediately after the delivery of the $1^{\text {st }}, 4^{\text {th }}$ and $8^{\text {th }}$ piglet, respectively. Following application of sterile gel on the skin surface, two transducers were attached to the sows' abdominal base, one for detecting uterine activity and the other for monitoring fetal heart rate. Monitoring started from the expulsion of the first piglet to the completion of parturition. In our experience, cardio-tocographic monitoring during delivery has proven to be useful for the early identification of serious problems during parturition and of fetal distress. However, since it was not possible to know which fetus was close to the fetal transducer, we did not include this variable in the analyses of the outcomes.

Uterine activity and pregnancy outcomes: We considered as the start of uterine activity when an evident change in the activity was observed in the tocogram at the beginning of parturition. The end was considered when the uterine activity returned to a pre-labor pattern and all piglets had been delivered. During parturition, intensity $(\mathrm{mmHg})$, frequency (contractions per min) and duration (seconds) of oxytocin-induced contractions were monitored by means of an electronic digital cardiotocograph (Fetal Monitor 
Coriometric, Medical Systems Inc. Co., Connecticut, CN, USA). We also quantified the time (min) elapsed from the intramuscular administration of oxytocin to the presence of evident uterine contractions (time of latency), the time interval (min) between each piglet, and the overall duration (min) of labor.

Neonatal outcomes: Numbers of liveborn piglets, meconium-stained piglets and stillbirths were recorded. The latter were classified according to criteria previously described in detail elsewhere (Mota-Rojas et al., 2002; Mota-Rojas et al., 2005). Briefly, type-I stillbirths occur in the prepartum period whereas type-II stillbirths occur during parturition and they are generally associated with anoxia and dystocia. In order to overcome the natural differences in the number of piglets born to each sow, data were adjusted to per every 100 piglets.

The $\mathrm{pH}$ of umbilical blood was obtained by means of a digital potentiometer (Model KS-701 with a CH701 electrode, Cropovet S.A. de C.V., Zapopan, Jalisco, Mexico) from a blood sample obtained in all piglets after the umbilical cord was ruptured. During sampling, no distinction was performed between arterial and venous blood. Body temperature was obtained by means of a tympanic membrane thermometer. Both $\mathrm{pH}$ and body temperature were taken at $1 \mathrm{~min}$ after birth in all piglets.

Data analysis: Data were stored in electronic form specially designed for controlling swine's production and development in the farm. Data on the number and intensity of uterine contractions were obtained by two of the investigators from the printed tocogram. A mean value was estimated for every sow and was used for the analysis.

Continuous variables were compared among the four groups by means of an ANOVA test and if $P<0.05$, a Dunnett analysis was performed for comparisons between control and each of the 3 treated groups. The Kruskal-Wallis test was used to compare the number of piglets born to each sow among the four groups. Since the $\mathrm{pH}$ is a $\log _{10}$ value, data from live born piglets without meconium stain were compared among the groups by means of the KruskalWallis test. The $\mathrm{pH}$ and body temperature of meconium-stained piglets were also analyzed in order to test whether these parameters reflected quantitative measurements of adverse effects of oxytocin in the piglets. Since this was $a$ posteriori analysis and, as mentioned above, $\mathrm{pH}$ represents a $\log _{10}$ value, we decided to compare these parameters among the 4 groups by means of the KruskalWallis test. When the Kruskal-Wallis test result was statistically significant, a MannWhitney test was used to compare any of the variables between the control group and any of the 3 treated groups. Categorical variables were compared among groups by the $x^{2}$ test. If $P<0.05$, the odds ratio (OR) and $95 \%$ confidence interval were obtained. The statistical analyses were performed by StatsDirect v. 2.4.1 (Cheshire, United Kingdom). A two-tailed $P<0.05$ was considered the significant limit for every test.

\section{RESULTS}

In the 3 groups that received oxytocin, the overall duration of labor was approximately 20 to $40 \mathrm{~min}$ shorter than control group ( $P$ $<0.0001$ ) (Table 1). The time of latency of oxytocin was approximately $23-25 \mathrm{~min}$ in the treated groups. The time interval between piglets was reduced approximately 3 to $5 \mathrm{~min}$ in the treated groups in comparison to the control group $(P<$ $0.0001)$. Although the difference remained statistically different, the effects were less evident in group O-8. The number of uterine contractions was similar between the control group and groups $\mathrm{O}-1$ and O-4, but they were significantly less frequent in group O-8 than in the control group. The duration and intensity of contractions reached maximum values in group $\mathrm{O}-1$ but evidently decreased when oxytocin was administered later. In order to illustrate such changes, typical tocograms obtained from controls and sows receiving oxytocin at different periods of labor are shown in Figure 1. 
TABLE 1

Uterine response to oxytocin i.m. $0.083 \mathrm{IU} / \mathrm{kg}$ administered at different times of labor in sows

\begin{tabular}{|c|c|c|c|c|}
\hline Sows (n) & $\begin{array}{c}\text { Control group } \\
50\end{array}$ & $\begin{array}{l}\text { Group O-1 } \\
50\end{array}$ & $\begin{array}{l}\text { Group } \mathrm{O}-4 \\
50\end{array}$ & $\begin{array}{c}\text { Group O-8 } \\
50\end{array}$ \\
\hline Overall duration of labor $(\mathrm{min})^{\mathrm{a}}$ & $188.7 \pm 17.4$ & $144.5 \pm 48.9$ & $143.7 \pm 29.3$ & $161.7 \pm 29.5$ \\
\hline Latency of oxytocin $(\min )^{b}$ & - & $25.6 \pm 4.6$ & $23.4 \pm 3.2$ & $24.3 \pm 4.3$ \\
\hline Time interval between babies $(\mathrm{min})^{\mathrm{c}}$ & $18.0 \pm 2.4$ & $13.9 \pm 5.0$ & $13.8 \pm 3.3$ & $15.7 \pm 3.1$ \\
\hline Uterine contractions ( $\mathrm{n} \times 10$ births) ${ }^{\mathrm{d}}$ & $41.6 \pm 8.5$ & $40.7 \pm 6.4$ & $39.6 \pm 6.4$ & $35.6 \pm 5.2$ \\
\hline Duration of contractions (seconds) ${ }^{\mathrm{e}}$ & $11.6 \pm 4.5$ & $18.0 \pm 4.5$ & $16.5 \pm 4.1$ & $12.8 \pm 4.4$ \\
\hline Intensity of contractions $(\mathrm{mm} \mathrm{Hg})^{\mathrm{f}}$ & $11.6 \pm 2.0$ & $16.3 \pm 3.0$ & $15.3 \pm 2.8$ & $14.2 \pm 3.1$ \\
\hline
\end{tabular}

Animals in groups O-1, O-4 and O-8 received intramuscularly oxytocin at a dose of 0.083 IU/kg (approximately $1 \mathrm{IU} / 12 \mathrm{~kg}$ ) immediately after the delivery of the $1^{\text {st }}, 4^{\text {th }}$ and $8^{\text {th }}$ piglet, respectively.

Except where specified, data are mean \pm SD and comparisons among the four groups were performed by a one-way ANOVA test

${ }^{a} P<0.0001$; data in the three treated groups were significantly lower (at least $P<0.001$ ) than control group (Dunnett test)

${ }^{\mathrm{b}} P=0.03$; a significant difference $(P=0.02)$ was observed between the second and third groups (Tukey test)

${ }^{\mathrm{c}} P<0.0001$; data in the three treated groups were significantly lower (at least $P<0.005$ ) than control group (Dunnett test)

${ }^{\mathrm{d}} P<0.0001$; a significant difference $(P<0.0001)$ was observed between the fourth and control groups (Dunnett test)

${ }^{\mathrm{e}} P<0.0001$; significant differences $(P<0.0001)$ were observed between the control and either the second and third groups (Dunnett test)

${ }^{\mathrm{f}} P<0.0001$; data in the three treated groups were significantly higher $(P<0.0001)$ than the control group (Dunnett test)

As expected, the number of piglets born per sow was similar in the four groups $(P=$ 0.9 ) and ranged from 8 to 14 piglets (Table 2). In parallel to the uterine changes, meconium-stained piglets in group $\mathrm{O}-1$ was 2.5 times greater than controls but in group O-8 were approximately $68 \%$ fewer than controls. This relationship was more evident with intrapartum deaths. The rate was similar between controls and Group O1 (approximately 6\% in both groups) but decreased with time at which oxytocin was administered during parturition and was as low as $1.7 \%$ in group O-8 (Table 2). The time at which death occurred was different among the 4 groups (Figure 2). In the control group, the higher number of intrapartum deaths occurred from the $7^{\text {th }}$ to $9^{\text {th }}$ piglet. However, in group $\mathrm{O}-1$ the intrapartum deaths evidently peaked at the $3^{\text {rd }}-5^{\text {th }}$ piglet. In group $\mathrm{O}-4$, the higher rates of this type of stillbirths were observed between the $5^{\text {th }}$ and $6^{\text {th }}$ piglet. Finally, in group $0-8$ the higher rates of intrapartum deaths were observed from the $9^{\text {th }}$ to $10^{\text {th }}$ piglet (Figure 2).

The umbilical cord $\mathrm{pH}$ levels in piglets without any evidence of meconium stain were 7.40 (7.20 to 7.81) [median (ranges)], 7.40 (6.90 to 7.80$), 7.40$ (7.0 to 7.80$)$, and 7.40 (7.12 to 7.70$)$ in control group and groups $\mathrm{O}-1, \mathrm{O}-4$ and $\mathrm{O}-8$, respectively $(\mathrm{P}<$ 0.005 ; Kruskal-Wallis test). Differences were observed between the controls and either group O-1 $(P<0.0001)$ and $\mathrm{O}-4$ $(P<0.025)$ due to the lower limits.

In meconium-stained piglets, umbilical cord $\mathrm{pH}$ levels were statistically lower by approximately 0.8 units in the three treated groups than in controls (Table 2). Finally, body temperature in the newborn piglets showed a reduction of approximately $0.5^{\circ} \mathrm{C}$ to $1.3^{\circ} \mathrm{C}$ in groups $\mathrm{O}-1$ and $\mathrm{O}-4$ but piglets in the group $\mathrm{O}-8$ showed a modest but significantly higher body temperature over controls. 

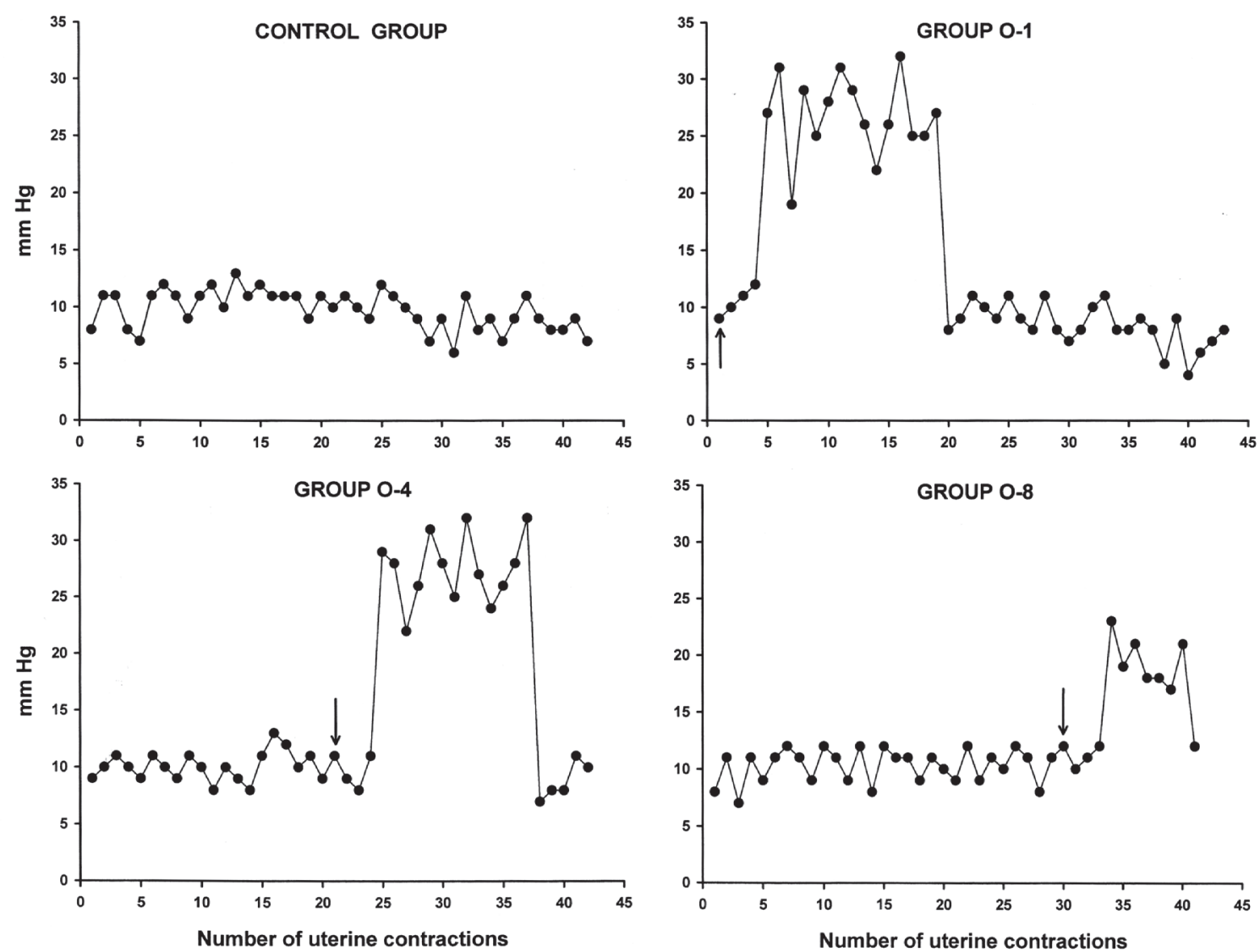

Figure 1: Typical tocograms of control sows (Group 1) and sows that received intramuscularly oxytocin $0.083 \mathrm{IU} / \mathrm{kg}$ immediately after the parturition of the $1^{\text {st }}, 4^{\text {th }}$ and $8^{\text {th }}$ piglet (Groups O- 1 , O4 and $\mathrm{O}-8$, respectively). The arrow represents time at which oxytocin was administered. The tocograms were plotted as intensity of uterine contractions $(\mathrm{mm} \mathrm{Hg}$; y-axis) according to the progressive number of uterine contraction (x-axis).

\section{DISCUSSION}

In this study, uterotonic effects secondary to the intramuscular administration of oxytocin in parturient sows varied according to the time of administration, producing more intense and prolonged contractions at the beginning and middle than at the end of labor. These changes were in parallel to the incidence of adverse fetal outcomes. In pigs, the uterine body is branched anteriorly into 2 uterine horns where fetuses develop throughout pregnancy in very similar numbers in the two horns. The uterus is formed by longitudinal and circular muscles. The porcine corneal longitudinal muscle is innervated by adrenergic nerves whereas the circular muscle is innervated by cholinergic nerves. Although both of them respond to similar bioactive substances, the responsiveness to oxytocin was observed to be higher in longitudinal than circular muscle (Kitazawa et al., 2001). Gestation-related changes in uterine activity include alterations in hormonal, metabolic, and neural inputs to the uterus as well as changes in the responsiveness of the myometrium to bioactive substances through alterations in receptors and coupled signal transduction mechanisms resulting in myometrial layer-dependent differences in responsiveness to bioactive substances less marked than those observed in non-pregnant pigs (Kitazawa et al., 2003). 
TABLE 2

Adverse fetal outcomes to oxytocin i.m. $0.083 \mathrm{IU} / \mathrm{kg}$ administered at different times of labor in pigs

\begin{tabular}{|c|c|c|c|c|}
\hline & Control group & Group 0-1 & Group 0-4 & Group 0-8 \\
\hline Piglets per sow [median (ranges)] $]^{\mathrm{a}}$ & $10(9-14)$ & $10(8-13)$ & $10(8-14)$ & $10(9-13)$ \\
\hline Meconium-stained piglets ( $\mathrm{n} \times 100$ piglets) ${ }^{\mathrm{b}}$ & 4.0 & $10.1^{\mathrm{f}}$ & 5.1 & $1.3^{\mathrm{g}}$ \\
\hline Intrapartum deaths (n x 100 piglets) ${ }^{c}$ & 6.4 & 6.1 & 4.4 & $1.7^{\mathrm{h}}$ \\
\hline Meconium-stained piglets (n): & 21 & 53 & 27 & 7 \\
\hline $\mathrm{pH}[\text { median (ranges) }]^{\mathrm{d}}$ & $7.31(7.20-7.81)$ & $7.23(6.90-7.80)$ & $7.23(7.00-7.80)$ & $7.22(7.12-7.30)$ \\
\hline Body temperature $\left({ }^{\circ} \mathrm{C}\right)[\text { median (ranges) }]^{e}$ & $38.1(36.9-38.4)$ & $36.8(35.8-37.9)$ & $37.6(36.9-38.2)$ & $38.3(37.9-38.5)$ \\
\hline
\end{tabular}

Animals in groups O-1, O-4 and O-8 received intramuscularly oxytocin at a dose of $0.083 \mathrm{IU} / \mathrm{kg}$ (approximately $1 \mathrm{IU} / 12 \mathrm{~kg}$ ) immediately after the delivery of the $1^{\text {st }}, 4^{\text {th }}$ and $8^{\text {th }}$ piglet, respectively.

aKruskal-Wallis test; $P=0.9$

${ }^{\mathrm{b}}$ Total $\mathrm{x}_{-}=43.1 ; P<0.0001$

'Total $\mathrm{x}_{-}=16.2 ; P=0.001$

${ }^{\mathrm{d} K r u s k a l-W a l l i s}$ test; $P=0.008$; in the three treated groups, the umbilical cord $\mathrm{pH}$ was significantly lower than controls (at least $P<0.02$; Mann-Whitney U test)

${ }^{e}$ Kruskal-Wallis test; $P<0.0001$; in groups 2 and 3 , the body temperature was significantly lower than control group (at least $P<0.01$; Mann-Whitney $\mathrm{U}$ test), but in group 4 it was significantly higher $(P<0.01$; MannWhitney U test).

fOdds ratio $=2.7(95 \%$ CI 1.6 to 4.6$)$

gOdds ratio $=0.26(95 \%$ CI 0.12 to 0.54$)$

${ }^{\mathrm{h}}$ Odds ratio $=0.33(95 \% \mathrm{CI} 0.14$ to 0.78$)$

In pregnant mammals including humans, an abrupt increase in oxytocin binding sites in the uterus may occur at approximately 24 $\mathrm{h}$ before the onset of labor, reaching the greatest levels during labor and sharply decreasing after parturition to reach baseline levels 2-5 days postpartum (Alexandrova and Soloff, 1980; Fuchs et al., 1984; Soloff, 1990). An increase in myometrial sensitivity to oxytocin and plasma oxytocin levels was observed to occur simultaneously to the increase in the number of oxytocin receptors (Soloff, 1990). In comparison to non-pregnant myometrium, the RNA level of oxytocin receptor messenger increases 100 -fold at 32 weeks and $>300$-fold at the onset parturition (Kimura et al., 1996). Oxytocin stimulates uterine contractions by mechanisms involving activation of receptor-operated calcium channels and release of calcium from the sarcoplasmic reticulum (Zeeman et al., 1997). The maximum oxytocin-induced contractions of longitudinal muscle have regional variations, being similar in the horns and corpus and lower in the cervix (Kitazawa et al., 2001). This gradation of contractile responsiveness of oxytocin would lead to a pressure gradient within the uterus which could expel uterine content.

Based on its pharmacokinetics, oxytocin may be administered as a single bolus dose or as an infusion. In humans, the plasma half-life of oxytocin is very short, ranging from 0.17 to 0.25 hours in pregnant women and its clearance during labor is five times faster than in the postpartum period, approximately 100 vs. $20 \mathrm{~mL} / \mathrm{min} \times 1 / \mathrm{kg}$, respectively (Hardman et al., 2001). However, the optimum time period at which oxytocin should be administered for labor induction has not been clearly defined. In a recent clinical trial, although the sample size was too small to show statistically significant differences, it was observed that the administration of oxytocin throughout labor could increase certain unplanned 

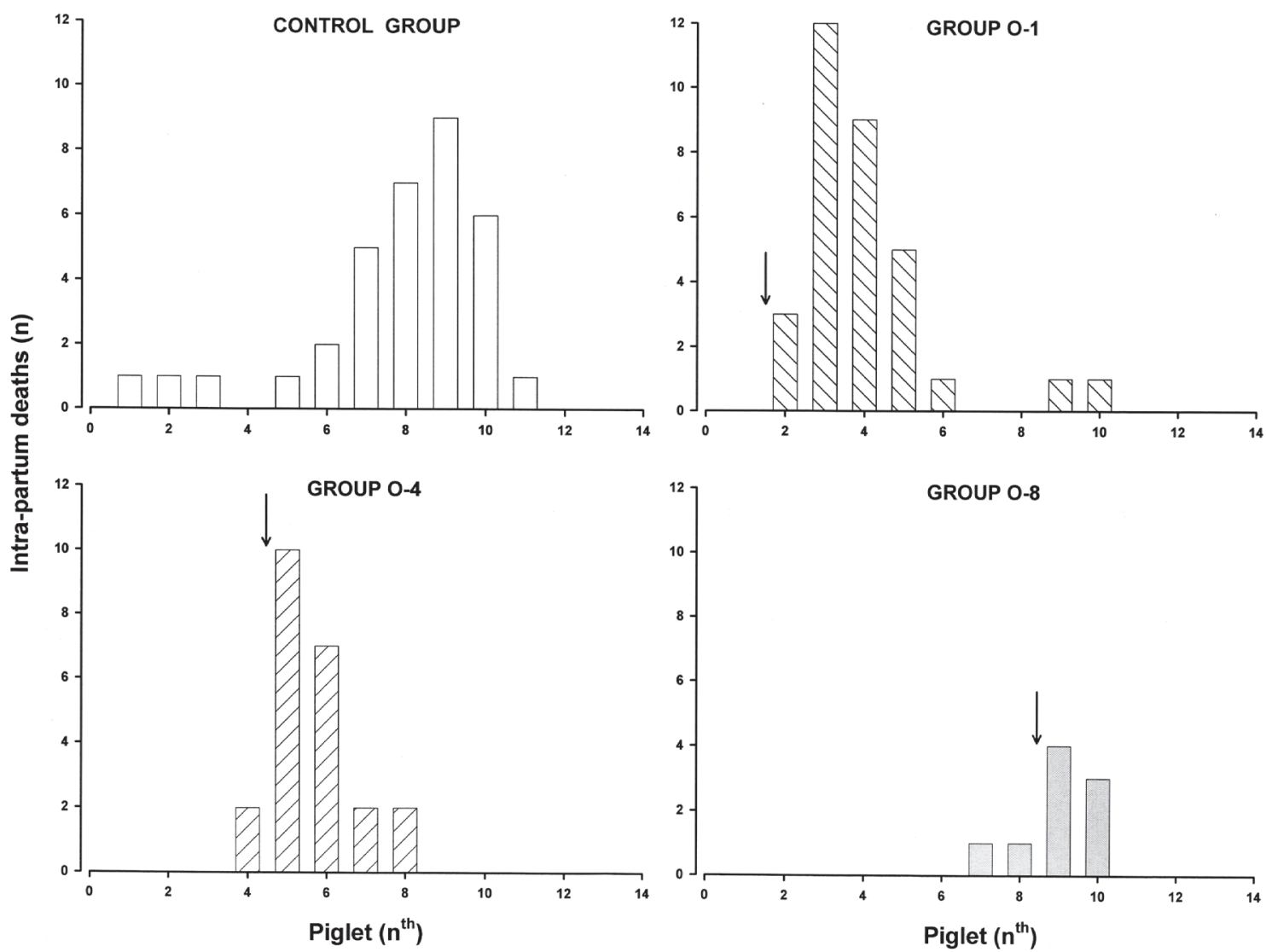

Figure 2: The time at which intrapartum deaths occurred varied according to the group. In controls (top left plot), more number of deaths occurred between the $8^{\text {th }}$ and $10^{\text {th }}$ piglet. In contrast, death in treated groups were more related to time at which oxytocin was administered. Oxytocin was administered after the born of the $1^{\text {st }}, 4^{\text {th }}$ and $8^{\text {th }}$ piglet in groups O-1, O-4 and O-8, respectively.

pregnancy outcomes such as cesarean sections, vacuum extraction and uterine hyperstimulation compared to when oxytocin was discontinued when cervical dilation reached $5 \mathrm{~cm}$ (Daniel-Spiegel et al., 2004). Oxytocin administered in the third stage of labor has proven benefits (Golan et al., 1983; Reddy and Carey, 1989; WilkenJensen et al., 1989; Golan, 1990; Straw et al., 2000). Our results support that at least in sows there is a critical period at which oxytocin may produce deleterious fetal effects due to its potent uterotonic effects. It is hypothesized that during early labor, the uterus has a good responsiveness to either endogenous or exogenous oxytocin. Due to the proliferation of oxytocin receptors, this responsiveness may not be saturated by endogenous oxytocin and therefore exogenous administration of this hormone was able to favor its uterotonic effects. Uterine hyperstimulation may decrease uterine blood supply that may subsequently result in fetal distress (Sherwin et al., 2003).

It is likely that oxytocin administered late in parturition sufficiently stimulates the uterus even when the muscles were fatigued but without substantially decreasing the blood flow which leads to a reduced rate of adverse fetal events. Oxytocin receptor mRNA in myometrium increases almost 50 times after 12 hours of labor (Adachi and $\mathrm{Oku}, 1995)$. However, it is very unlikely that the concentration increase in our 2-4 hour long study period is enough to be physiologically important.

In humans, oxytocin is considered the uterotonic agent of choice for prevention 
and treatment of postpartum hemorrhage (Miller et al., 2004). This efficacy may be supported by our results since the uterus was able to respond to oxytocin at advanced stages of the parturition process. On the other hand, it has been demonstrated that oxytocin is not transferred across the placenta in sheep and humans (Patient et al., 1999; Glatz et al., 1980). In addition, the placenta in pigs is epitheliochorial (it has two complete epithelia and isolates the fetus from the mother) and in humans it is hemochorial (it provides direct access to maternal blood for oxygen- $\mathrm{CO}_{2}$ exchange and other maternal-fetal transport including glucose and aminoacids) (Enders and Carter, 2004), we therefore consider that our results were related to the actions of oxytocin on the uterine muscle without any direct effects on the piglets.

In conclusion, this study supports that oxytocin administered to sows at early phases of parturition may result in an increased duration and intensity of uterine contractions, subsequently decreasing placenta perfusion and producing adverse fetal outcomes. However, oxytocin administered late in labor may result in mild uterotonic effects but with better fetal outcomes than controls. These changes in oxytocin response may be explained physiologically by changes in uterine muscular responsiveness produced during the time course of parturition.

\section{ACKNOWLEDGEMENTS}

The study was part of the $\mathrm{PhD}$ thesis of Daniel Mota-Rojas at the Doctorate Program in Biological Sciences of the Universidad Autónoma Metropolitana in México DF where he was supported by the scholarship No. 176363 from CONACYT. The study was supported by a grant from the Programa de Mejoramiento al Profesorado (PROMEP) UAM-PTC-028 to the Academic Staff of Etología, Producción Porcina y Fauna Silvestre. Daniel MotaRojas, M. Alonso-Spilsbury and M.E. Trujillo were supported, as members, by the Sistema Nacional de Investigadores.

\section{REFERENCES}

ADACHI S, OKU M (1995) The regulation of oxytocin receptor expression in human myometrial monolayer culture. J Smooth Muscle Res 31: 175-187

ALEXANDROVA M, SOLOFF MS (1980) Oxytocin receptors and parturition. I. Control of oxytocin receptor concentration in the rat myometrium at term. Endocrinology 106: 730-735

DANIEL-SPIEGEL E, WEINER Z, BEN-SHLOMO I, SHALEV E (2004) For how long should oxytocin be continued during induction of labour? BJOG 111: 331334

ENDERS AC, CARTER AM (2004) What can comparative studies of placental structure tell us? A review. Placenta 25 Suppl. A: s3-s9

FUCHS AR, FUCHS F, HUSSLEIN P, SOLOFF MS (1984) Oxytocin receptors in the human uterus during pregnancy and parturition. Am J Obstet Gynecol 150: 734-741

GILBERT CL (1999) Oxytocin secretion and management of parturition in the pig. Reprod Domestic Anim 34: 193-200

GLATZ TH, WEITZMAN RE, NATHANIELSZ PW, FISHER DA (1980) Metabolic clearance and transplacental passage of oxytocin in the pregnant ewe and fetus. Endocrinology 106: 1006-1011

GOLAN A (1990) Volume and timing are key to use of intraumbilical oxytocin for management of retained placenta. Am J Obstet Gynecol 162: 1628-1629

GOLAN A, LIDOR AL, WEXLER S, DAVID MP (1983) A new method for the management of the retained placenta. Am J Obstet Gynecol 146: 708-709

HARDMAN JG, LIMBIRD LE, GOODMAN GILMAN A (2001) Goodman \& Gilman's The pharmacological basis of therapeutics. $10^{\text {th }}$ Edition, International Edition: McGraw-Hill Medical Publishing Division. p. 1993.

KIMURA T, TAKEMURA M, NOMURA S, NOBUNAGA $\mathrm{T}$, KUBOTA $\mathrm{Y}$, INOUE $\mathrm{T}$, HASHIMOTO $\mathrm{K}$, KUMAZAWA I, ITO Y, OHASHI K, KOYAMA M, AZUMA C, KITAMURA Y, SAJI F (1996) Expression of oxytocin receptor in human pregnant myometrium. Endocrinology 137: 780-785

KITAZAWA T, HATAKEYAMA H, CAO J, TANEIKE T (2003) Pregnancy-associated changes in responsiveness of the porcine myometrium to bioactive substances. Eur J Pharmacol 469:135-144

KITAZAWA T, KAJIWARA T, KIUCHI A, HATAKEYAMA H, TANEIKE T (2001) Muscle layerand region-dependent distributions of oxytocin receptors in the porcine myometrium. Peptides 22: 963-974

LEMAN AD, KNUDSTON C, RODEFFER HE, MUELLER AG (1972) Reproductive performance of swine on 76 Illinois farms. J Am Vet Med Assoc 161: 1248-1250

MILLER S, LESTER F, HENSLEIGH P (2004) Prevention and treatment of postpartum hemorrhage: new advances for low-resource settings. J Midwifery Women's Health 49: 283-292

MOTA-ROJAS D, MARTÍNEZ-BURNES J, TRUJILLOORTEGA ME, ALONSO-SPILSBURY ML, RAMÍREZ-NECOECHEA R, LÓPEZ A (2002) Effect of oxytocin treatment in sows on umbilical cord morphology, meconium staining, and neonatal mortality of piglets. Am J Vet Res 63: 1571-1574

MOTA-ROJAS D, NAVA-OCAMPO AA, TRUJILLO ME, VELÁZQUEZ-ARMENTA Y, RAMÍREZNECOECHEA R, MARTÍNEZ-BURNES J, ALONSOSPILSBURY M (2005) Dose minimization study of oxytocin in early labor in sows: uterine activity and fetal outcome. Reprod Toxicol 20: 255-259 
PATIENT C, DAVISON JM, CHARLTON L, BAYLIS PH, THORNTON S (1999) The effect of labour and maternal oxytocin infusion on fetal plasma oxytocin concentration. Br J Obstet Gynaecol 106: 1311-1313

RANDALL GC (1972) Observations on parturition in the sow. II. Factors influencing stillbirth and perinatal mortality. Vet Rec 90:183-186

REDDY VV, CAREY JC (1989) Effect of umbilical vein oxytocin on puerperal blood loss and length of the third stage of labor. Am J Obstet Gynecol 160: 206-208

SHERWIN CM, CHRISTIANSEN SB, DUNCAN IJH, ERHARD HW, LAY DC, MENCH JA, O'CONNOR CE, PETHERICK JC (2003) Guidelines for the ethical use of animals in applied ethology studies. Appl Animal Behav Sci 81: 291-305
SOLOFF MS (1990) Oxytocin receptors in the uterus. In: CARSTEN ME, MILLER JD (eds) Uterine function: molecular and cellular aspects. New York: Plenum Press. pp. 373-392

STRAW BE, BUSH EJ, DEWEY CE (2000) Types and doses of injectable medications given to periparturient sows. J Am Vet Med Assoc 216: 510-515

WILKEN-JENSEN C, STROM V, NIELSEN MD, ROSENKILDE-GRAM B (1989) Removing a retained placenta by oxytocin - a controlled study. Am J Obstet Gynecol 161: 155-156

ZEEMAN GG, KHAN-DAWOOD FS, DAWOOD MY (1997) Oxytocin and its receptor in pregnancy and parturition: current concepts and clinical implications. Obstet Gynecol 89: 873-883 
